\title{
Yeraltı Maden Ocaklarında Aydınlatma Koşullarının Belirlenmesi
}

\author{
İbrahim ÇINAR ${ }^{1}$, Cem ŞENSÖĞÜT ${ }^{* 2}$ \\ ${ }^{1}$ Selçuk Üniversitesi, Mühendislik Fakültesi, Maden Mühendisliği Bölümü, Konya \\ ${ }^{2}$ Dumlupınar Üniversitesi, Mühendislik Fakültesi, Maden Mühendisliği Bölümü, Kütahya
}

Geliş tarihi: 24.02.2017 Kabul tarihi: 31.05.2017

Öz

Bu çalışmada, iş sağlığı ve güvenliği açısından çok önemli olan işyerlerinin aydınlatılması ile ilgili temel bilgiler verilerek iyi bir aydınlatmanın nasıl yapılması gerektiği açıklanmıştır. Yeraltı maden işletmelerinde yeterli aydınlatma koşullarının oluşturulmasının iş sağlığı ve güvenliği açısından önemi ifade edilmiştir. Ayrıca iki farklı yeraltı maden işletmesinde yapılan aydınlatma ölçümleri verilerek yasal sınırlamalar vurgulanmış, yetersiz aydınlatma durumunda yapılması gerekenler ve yaşanabilecek olumsuz durumlar hakkında bilgi verilmiştir

Anahtar Kelimeler: Yeraltı madenciliği, Aydınlatma, İş sağlığı ve güvenliği, Lüks

\section{Determination of Illumination Conditions in Underground Mines}

\begin{abstract}
In the present work, an explanation how to make a good illumination is given together with the basic information about lighting. The importance of establishing sufficient lighting conditions in underground mines has been emphasized in terms of occupational health and safety. In addition, legal limitations are also declared by presenting illumination measurements made in two different underground mines and information about what to do in case of inadequate lighting and the possible negative situations are also mentioned.
\end{abstract}

Keywords: Underground mining, Lighting, Occupational health and safety, Lux

"Sorumlu yazar (Corresponding author): Cem ŞENSÖĞÜT, sensogut@dpu.edu.tr 


\section{GíRiş}

Günümüzde, diğer endüstri dallarına göre maden ocağı aydınlatılması konusunda çok fazla çalışma yapılmadığı görülmektedir. Görme, iş yerlerinde en çok ihmal edilen parametrelerdendir. Oysaki çalışanların sağlığının korunması için gerekli fiziksel şartların başında "aydınlatma” gelmelidir. Aydınlatmanın görsel etkisinin yanında çalışanın kendini iyi hissetmesi, moralinin yüksek olması ve yorgunluk hissetmemesi gibi biyolojik ve psikolojik etkileri de bulunmaktadır [1].

Yeraltı maden ocaklarında aydınlatmanın temel amacı, çalışmalar sırasında yeterli bir görme alanı oluşturarak emniyeti artırmak ve görüş alanında çalışanın tehlikeleri önceden fark ederek önlem almasına imkân tanımaktır.

Bir iş ortamının aydınlatma ihtiyacı; yapılan işin özelliklerine, o yerde çalışan insanların göz fonksiyonlarının normalliğine ve işin özellikleri nedeniyle detay algılama gibi ölçütlere bağlıdır. Özellikle yaşlı çalışanların bulunduğu işyerlerinde aydınlatma derecesinin en uygun bir düzeyde bulunması gerekmektedir [2].

İyi aydınlatılmamış bir ortamda yapılan çalışmalarda, görme bozuklukları, kazalar ve malzeme kayıları meydana gelmekte ve üretim miktarı düşmektedir. Özellikle hassas iş yapılan yerlerde yetersiz aydınlatma, çalışanın verimliliğini de azaltmaktadır [3].

\section{AYDINLATMA}

Nesnelere, bunların çevrelerine ya da bir bölgede görülebilmeleri için 1 şı uygulamasına "aydınlatma", bir yüzeye düşen 1şık miktarı ise "aydınlatma şiddeti" olarak ifade edilmektedir. Aydınlatma şiddetinin birimi ise lüks (lx)'tür. $11 \mathrm{x}=11 \mathrm{~m} / \mathrm{m}^{2}\left(1 \mathrm{~m}^{2}\right.$ yüzey üzerine düzgün dağılmış 1 lümen 1 şık akısının oluşturduğu aydınlık) olarak tanımlanmaktadır [4].

İyi bir aydınlatma için, bir işyerinin aydınlatma düzeni bazı koşulları içermelidir. $\mathrm{Bu}$ koşullar aşağıda sıralanmıştır [5]:
- Kullanılan ışı̆̆ın niteliği uygun olmalıdır,

- Aydınlatma tekdüze olmalıdır,

- Aydınlatma durağan olmalıdır,

- Aydinlatma göz kamaşmasına neden olmamalıdır ve

- Çalışılan yüzeye gölge düşmemelidir.

İşyerlerinde bazı alanlarda ve işlerde gerekli aydınlatma şiddetleri Çizelge 1'de verilmiştir [6].

Çizelge 1. İşyerlerinde bazı alanlarda ve işlerde gerekli aydınlatma şiddeti değerleri

\begin{tabular}{|l|c|}
\hline İşyeri & $\begin{array}{c}\text { Aydınlatma } \\
\text { Şiddeti, Lüks }\end{array}$ \\
\hline $\begin{array}{l}\text { Koridorlar ve depolama } \\
\text { alanları }\end{array}$ & 100 \\
\hline Ofis çalışmaları & 500 \\
\hline $\begin{array}{l}\text { Yüzey hazırlama ve } \\
\text { boyama }\end{array}$ & 750 \\
\hline $\begin{array}{l}\text { Montaj, kalite kontrol ve } \\
\text { renk kontrolü }\end{array}$ & 1000 \\
\hline
\end{tabular}

İşçinin tehlikeli bir durumu fark edebilmesi ve hemen önlem alabilmesi, iyi bir aydınlatma sistemi ile orantılıdır. Ayrıca, maden işçileri arasında homojen olmayan düşük aydınlatma seviyesinden dolayı en çok Nystagmus hastalığı (istemsiz göz hareketi) görülür. Nystagmusun göz bebeğinin dengesini kaybetmesi, baş ağrısı, baş dönmesi ve gece görmelerinin kaybolması gibi belirtileri vardır [7].

Yeraltı maden işletmelerinde çalışma yerlerine göre aydınlatma şiddetleri Çizelge 2'de verilmiştir [8].

Standartlarda bahsi geçen değerler, genç çalışanlar üzerinden belirlenmiştir. Buna göre 20-25 yaş arasında çalışanın ihtiyaç duyduğu aydınlatma şiddeti çarpanını 1 kabul edilir ise; 40-50 yaş için 1,2 ; 51-65 yaş için 1,6 ve 65 yaş üzeri için 2,7 olarak kabul edilir [1].

Yetersiz aydınlatma tüm endüstriyel kazaların $\% 5$ 'inin tek sorumlusu olup \%20'sinde de belirli rol oynamaktadır. Aydınlatmanın sadece baret lambalarıyla sağlandığı bir ocakta, genel 
aydınlatma kullanıldığında üretimin kişi başına iki ay içinde $\% 5$ arttığ 1 tespit edilmiş ve daha uzun süreli olarak yapıldığında kişi başı üretimin \%26'ya yakın oranlarda arttığı gözlenmiştir [9].

Yeraltı kömür ocağında yapılan ölçümlerde; lokomotif farı aydınlatma şiddeti $1 \mathrm{~m}$ uzaklıkta 280 lüks iken $9 \mathrm{~m}$ uzaklıkta 4 lüks olarak ölçülmüştür. Baret lambası ise $1 \mathrm{~m}$ uzaklıkta 180 lüks iken $13 \mathrm{~m}$ uzaklıkta 0 lüks olarak ölçülmüştür [10].

Çizelge 2. Maden İşletmelerinde çalışma yerlerine göre aydınlatma şiddeti değerleri

\begin{tabular}{|c|c|c|c|}
\hline \multirow{3}{*}{ LOKASYON } & \multicolumn{3}{|c|}{$\begin{array}{c}\text { Ortalama Aydınlatma Gücü, } \\
\text { Lüks }\end{array}$} \\
\hline & \multirow[b]{2}{*}{$\begin{array}{c}\text { Yalnız } \\
\text { Genel } \\
\text { Aydınlatma }\end{array}$} & \multicolumn{2}{|c|}{$\begin{array}{c}\text { Ek } \\
\text { Aydınlatmalı } \\
\text { Genel } \\
\text { Aydınlatma } \\
\end{array}$} \\
\hline & & 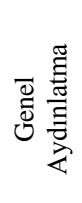 & 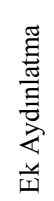 \\
\hline Atölyeler & 120 & 60 & 250 \\
\hline $\begin{array}{l}\text { Kuyu kazı yeri, Kırma } \\
\text { tesisleri, Vinç dairesi, } \\
\text { Ambarlar, Pompa } \\
\text { dairesi, Galeri alınları, } \\
\text { Şalter/Trafo dairesi, } \\
\text { Redresor dairesi }\end{array}$ & 80 & 40 & 150 \\
\hline $\begin{array}{l}\text { Ana kuyu katbaşları, } \\
\text { İstasyonlar }\end{array}$ & 40 & - & - \\
\hline $\begin{array}{l}\text { Konveyör aktarma } \\
\text { yerleri, Dolgu } \\
\text { makineleri, Büyük } \\
\text { tumba yerleri, Yükleme } \\
\text { yerleri }\end{array}$ & 30 & - & - \\
\hline $\begin{array}{l}\text { Galeri kavşakları, } \\
\text { Personel istasyonları, } \\
\text { Makaslar }\end{array}$ & 15 & - & - \\
\hline
\end{tabular}

\section{MADEN ISSLETMELERINDE AYDINLATMA KOŞULLARI}

Aydınlatma ölçümleri Tunçbilek Ömerler (İşletme 1) mekanize kömür işletmesinde ve Konya Beyşehir Dimin Madencilik (İşletme 2) yeraltı maden ocağında gerçekleştirilmiştir.
Ölçümlerde Stabila LD 300 Laser Meter (Şekil 2) [11] ve TES 1335 Light Meter (Şekil 3) [12] kullanılmıştır.

Ölçümler TS 2248'e göre; çalışılan yerlerle makine daireleri ve ambarların genel aydınlatılmasında, tabandan $1 \mathrm{~m}$ kadar yukarıda ve kuyubaşı, istasyon ve galerilerde ise tabandan $0,2 \mathrm{~m}$ yukarıda yatay düzlemde yapılmıştır.

İşletme 1'de yapılan ölçümler, desandreden başlanarak üretim yapılan B3 panosuna kadar toplam 33 noktada yapılmıştır. İşletme 2'de ise ölçümler ana galeri girişinden üretim panosuna kadar toplam 39 noktada yapılmıștır. Çalıșmalar sırasında tüm 1 şı kaynaklarının orta noktaları belirlenerek aydınlatmanın en düşük olduğu bölgelerde de ölçümler alınmıştır. Ölçüm sonuçları Şekil 4 ve 5 ile Çizelge 3 ve 4'de toplu olarak verilmiştir.

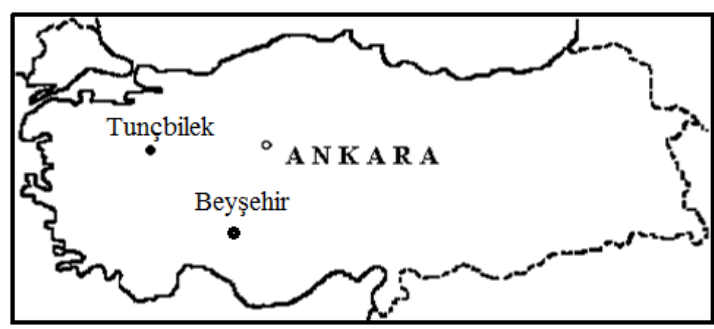

Şekil 1. Ölçüm alınan maden işletmelerinin yer bulduru haritası

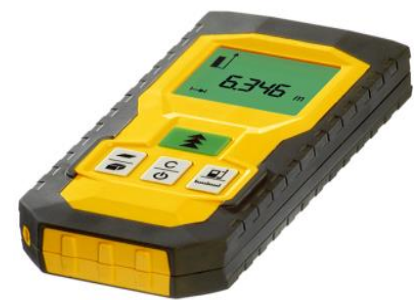

Şekil 2. Lazer metre Stabila LD 300

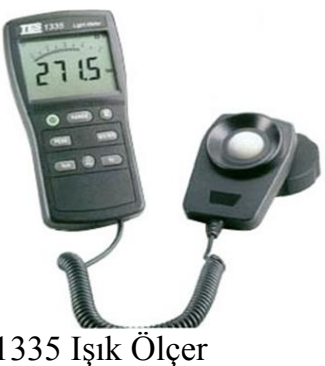


Çizelge 3. İşletme 1'e ait aydınlatma ölçüm sonuçları

\begin{tabular}{|c|c|c|c|c|c|c|c|c|c|c|c|}
\hline 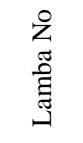 & 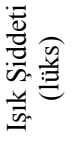 & 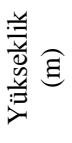 & 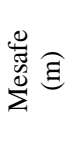 & 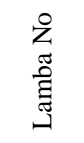 & 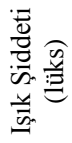 & $\begin{array}{l}\text { 咅 } \\
\text { 总 } \\
\vdots\end{array}$ & 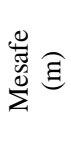 & 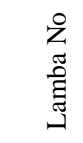 & 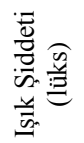 & 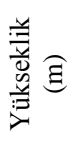 & 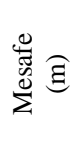 \\
\hline 1 & 66,7 & 2,34 & & 12 & 57,4 & 2,84 & & 23 & 64,7 & 1,91 & \\
\hline $1-2$ & 0,2 & & 30,0 & $12-13$ & 0,4 & & 23,2 & 24 & 132,2 & 2,84 & \\
\hline 2 & 30,1 & 3,02 & & 13 & 52,1 & 2,76 & & $24-25$ & 2,6 & & 40,0 \\
\hline $2-3$ & 0,7 & & 20,0 & 13-14 & 0,0 & & 47,5 & 25 & 56,2 & 3,07 & \\
\hline 3 & 48,8 & 2,93 & & 14 & 50,6 & 2,68 & & $25-26$ & 1,4 & & 23,5 \\
\hline $3-4$ & 0,7 & & 20,0 & $14-15$ & 0,4 & & 23,9 & 26 & 55,6 & 2,65 & \\
\hline 4 & 49,4 & 2,79 & & 15 & 66,1 & 2,82 & & $26-27$ & 0,7 & & 25,0 \\
\hline $4-5$ & 0,2 & & 25,0 & $15-16$ & 0,0 & & 48,0 & 27 & 62,4 & 2,65 & \\
\hline 5 & 42,5 & 2,84 & & 16 & 76,3 & 2,74 & & $27-28$ & 0,5 & & 13,0 \\
\hline $5-6$ & 1,3 & & 15,0 & 16-17 & 0,1 & & 23,9 & 28 & 47,5 & 2,93 & \\
\hline 6 & 73,6 & 2,71 & & 17 & 48,8 & 3,02 & & $28-29$ & 1,2 & & 20,0 \\
\hline 7 & 40,3 & 2,66 & & 18 & 93,2 & 2,56 & & 29 & 37,8 & 2,79 & \\
\hline \begin{tabular}{ll|}
$7-8$ \\
\end{tabular} & 0,6 & & 11,0 & 18-19 & 0,9 & & 13,6 & $29-30$ & 0,1 & & 25,0 \\
\hline 8 & 57,3 & 2,73 & & 19 & 84,5 & 1,92 & & 30 & 33,4 & 2,99 & \\
\hline \begin{tabular}{|c|}
$8-9$ \\
\end{tabular} & 0,1 & & 27,0 & $19-20$ & 0,7 & & 12,9 & $30-31$ & 0,0 & & 32,0 \\
\hline 9 & 46,7 & 2,92 & & 20 & 88,0 & 2,02 & & 31 & 35,8 & 2,77 & \\
\hline $9-10$ & 0,1 & & 28,0 & $20-21$ & 1,4 & & $\begin{array}{l}9,8 \\
\end{array}$ & $31-32$ & 0,1 & & 30,6 \\
\hline 10 & 48,8 & 2,85 & & 21 & 69,6 & 2,04 & & 32 & 41,3 & 2,86 & \\
\hline $10-11$ & 7,6 & & 8,5 & $21-22$ & 0,0 & & 14,6 & $32-33$ & 0,1 & & 37,8 \\
\hline 11 & 59,7 & 2,63 & & 22 & 44,8 & 2,06 & & 33 & 69,3 & 2,72 & \\
\hline 11-12 & 3,4 & & 9,4 & $22-23$ & 0,2 & & 12,0 & & & & \\
\hline
\end{tabular}

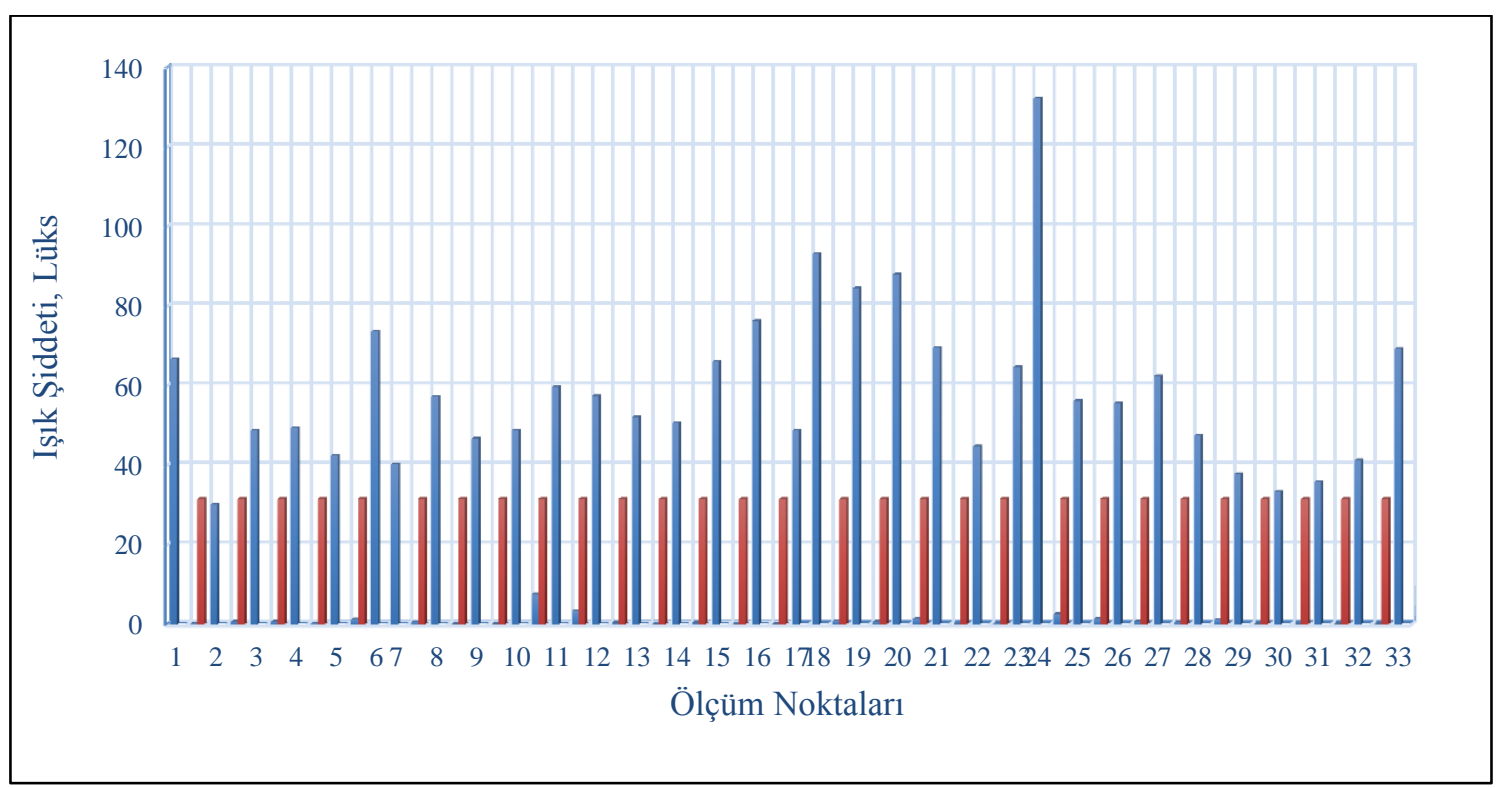

Şekil 4. İşletme 1'e ait ölçüm değerleri 
Çizelge 4. İşletme 2'ye ait aydınlatma ölçüm sonuçları

\begin{tabular}{|c|c|c|c|c|c|c|c|c|c|c|c|}
\hline 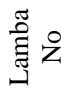 & 总离 & 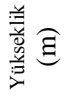 & 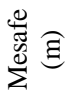 & 芯 & 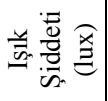 & 煎 & 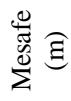 & 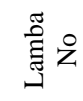 & 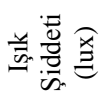 & 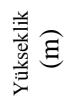 & 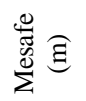 \\
\hline 1 & 183,0 & 2,55 & & 14 & 120,0 & 1,62 & & $27-28$ & 3,8 & & 15,6 \\
\hline $1-2$ & 1,0 & & 20,2 & 14-15 & 0,8 & & 7,0 & 28 & 90,0 & 1.53 & \\
\hline 2 & 150,0 & 1,78 & & 15 & 67,0 & 1,33 & & $28-29$ & 2,2 & & 25,8 \\
\hline $2-3$ & 0,8 & & 29,6 & 15-16 & 0,6 & & 11,1 & 29 & 170,0 & 1.29 & \\
\hline 3 & $\begin{array}{l}79,0 \\
\end{array}$ & 2,56 & & 16 & 50,0 & 1,62 & & $29-30$ & 6,5 & & 8,7 \\
\hline $3-4$ & 1,5 & & 8,1 & 16-17 & 0,5 & & 20,1 & 30 & 114,0 & 1.75 & \\
\hline 4 & 142,0 & 0,90 & & 17 & 47,0 & 2,05 & & $30-31$ & 4,3 & & 11,7 \\
\hline $4-5$ & 0,3 & & 23,3 & $17-18$ & 0,4 & & 17,2 & 31 & 149,0 & 1.63 & \\
\hline 5 & 90,0 & 1,92 & & 18 & 35,0 & 1,6 & & $31-32$ & 2,5 & & 12,5 \\
\hline $5-6$ & 0,6 & & 18 & 18-19 & 0,3 & & 18,1 & 32 & 104,0 & 2.05 & \\
\hline 6 & 43,0 & 2,55 & & 19 & 28,0 & 1,29 & & $32-33$ & 6,1 & & 10,4 \\
\hline $6-7$ & 0,5 & & 17,5 & 19-20 & 0,2 & & 21,0 & 33 & 93,0 & 2.12 & \\
\hline 7 & 13,0 & 2,46 & & 20 & 14,0 & 2,07 & & $33-34$ & 4,2 & & 13,5 \\
\hline $7-8$ & 0,5 & & 19,4 & $20-21$ & 0,1 & & 27,4 & 34 & 95,0 & 1.67 & \\
\hline 8 & 8,0 & 2,55 & & 21 & 7,0 & 1,97 & & $34-35$ & 3,0 & & 16,3 \\
\hline $8-9$ & 0,1 & & 16,4 & 22 & 144,0 & 1,77 & & 35 & 97,0 & 1.83 & \\
\hline 9 & 4,5 & 1,52 & & $22-23$ & 2,8 & & 15,6 & $35-36$ & 2,8 & & 15,7 \\
\hline $9-10$ & 0,1 & & 10,2 & 23 & 50,8 & 2,05 & & 36 & 89,0 & 2.13 & \\
\hline 10 & 3,0 & 2,08 & & $23-24$ & 5,7 & & 13,1 & $36-37$ & 2,3 & & 22,1 \\
\hline $10-11$ & 0,0 & & 11,1 & 24 & 105,0 & 2,55 & & 37 & 83,0 & 1.3 & \\
\hline 11 & 13,0 & 2,16 & & $24-25$ & 7,0 & & 8,3 & $37-38$ & 2,1 & & 8,6 \\
\hline $11-12$ & 0,3 & & 14,0 & 25 & 95,0 & 2,49 & & 38 & 89,0 & 1.49 & \\
\hline 12 & 25,0 & 1,24 & & $25-26$ & 4,5 & & 10,1 & $38-39$ & 2,7 & & 13,6 \\
\hline $12-13$ & 0,4 & & 5,2 & 26 & 97,0 & 1,63 & & 39 & $\begin{array}{l}98,0 \\
\end{array}$ & 1.82 & \\
\hline 13 & 75,0 & 1,64 & & $26-27$ & 3,6 & & 13,6 & & & & \\
\hline $13-14$ & 0,7 & & 25,3 & 27 & 95,0 & 1,54 & & & & & \\
\hline
\end{tabular}

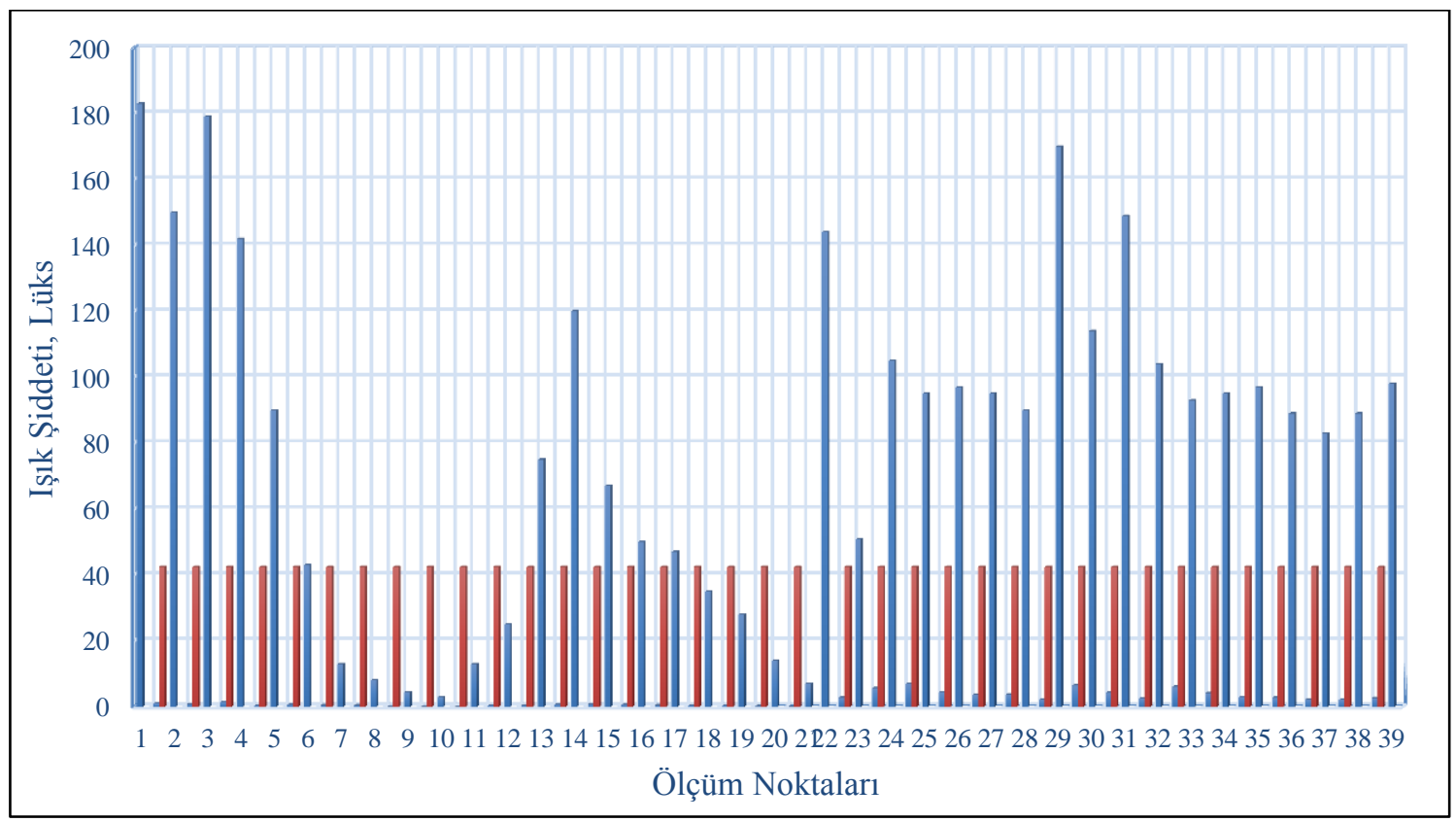

Şekil 5. İşletme 2'ye ait ölçüm değerleri 
Ölçülen değerlerin doğruluğu ve standart olması için yeraltı maden işletmelerinde kullanılan tepe lambası kapatılmıştır. Tepe lambaları açık olsa bile ocağın ortalama aydınlatma değerini çok az etkilediği görülmüştür. Tepe lambası sadece kısmi bir aydınlatma sağlamaktadır.

İşletme 1'de 62 farklı noktadan alınan ölçümlere göre ocağın ortalama aydınlatma değerinin 31,57 lüks olduğu görülmektedir. Bazı noktalarda alınan ölçümlerin ise 0 lüks'e kadar düştüğü görülmüştür.

İşletme 2'de 76 farklı noktadan alınan ölçümlere göre ocağın ortalama aydınlatma değerinin 42,50 lüks olduğu görülmektedir. Bazı noktalarda alınan ölçümlerin ise 0 lüks'e kadar düştüğü görülmüştür.

\section{SONUÇ VE ÖNERİLER}

Madenlerde iyi bir aydınlatma önemli olduğu kadar bu durumu oluşturmakta o derece zordur. Yeraltı ocaklarında aydınlatmanın en büyük problemi, aydınlatmanın tüm çalışma noktalarına götürülebilmesidir. Bunun nedenleri ocak faaliyetlerinin geniş alana yayılması ve çalışma alanlarının sürekli değişimidir.

Ayrıca, iyi aydınlatılmamış bir çalışma ortamında işçi yeterli görüş alanına sahip olmadığı için her türlü tehlike ile karşı karşıya kalacak, ciddi yaralanma, ölümle ya da maddi hasarlı kazalarla sonuçlanacaktır. Ayrıca iyi bir aydınlatma ile üretim miktarı ve verimlilik konularında artış sağlaması da beklenmektedir.

TS 2248 Standartı'nda belirtildiği gibi; genel aydınlatmada ortalama aydınlatma gücünün aydınlatılan yerin her tarafına yayılmış olmasına dikkat edilmelidir. Makine ve aygıtların çalışma ve kontrolü, aydınlatılan yerin bir bölümünde yapilıyorsa, ortalama aydınlatma gücünün bu bölümde sağlanması gerekir: Aydınlatılan yerin geri kalan kısmında ise, aydınlatma, ortalama aydınlatma gücü değerinin, \%50'sinden aşağıya düşmemelidir.
Her iki ocakta da yapılan ölçümler sonucunda iki 1şık kaynağı arasındaki aydınlatmanın yetersiz olduğu görülmektedir. Lambalar arası mesafenin fazla olmasından dolayı aydınlatma sorunu yaşanmaktadır.

Kullanılan floresan tipindeki aydınlatma lambaları, hem ekonomik açıdan hem de aydınlatma açısından istenilen düzeyde değildir. Yetersiz adınlatmanın olduğu bölgeler için daha ekonomik olan led aydınlatma düşünülebilir.

Ayrıca aydınlatma tesisinin bakımı da son derece önemlidir, lambaların zamanla bozulması veya tozlanması durumunda aydınlatma gücü düşecektir. Bu nedenle lambaların belirli sürelerle temizlenmesi ve bozulanların değiştirilmesi gerekmektedir.

Galeri tahkimatları ya kendi doğal renkleri ya da zamanla kömür veya taş tozu ile kaplanması nedeniyle koyu renklidirler. $\mathrm{Bu}$ durumda tahkimatların seçilememesi önemli bir sorun olmaktadır. Bu nedenle galerilerde uygun zaman aralığı sağlayacak biçimde badana yapılması uygun olacaktır.

\section{KAYNAKLAR}

1. Zeyrek, S., Kürkçü, E., Çakar, İ., 2014. İşyerlerinde Aydınlatma, İş Sağlığı ve Güvenliği Uygulamaları Rehberi, Çalışma ve Sosyal Güvenlik Bakanlığı Yayın No. 09, Ankara.

2. Hayta, A.B., 2007. Çalışma Ortamı Koşullarının İşletme Verimliliği Üzerine Etkisi, Gazi Üniversitesi Ticaret ve Turizm Eğitim Fakültesi Dergisi, No., Ankara.

3. Ilıcak, Ş., 1988. Çevre-İşyeri Koşulları ve Ergonomik Yaklaşımlar, 1. Ulusal Ergonomi Kongresi, MPM Yayınları, Yayın No. 372, Ankara.

4. Sirel, Ş., 1997. Aydınlatma Sözlüğü, Yap1 Fiziği Uzmanlık Enstitüsü Yayını, İstanbul

5. Yiğit, A., 2013. İş Güvenliği, Dora Yayıncılık Ltd. Şti., s375, Bursa. 
6. TS EN 12464-1, Işık ve Aydınlatma - Çalışma Yerlerinin Aydınlatılması - Bölüm 1: Kapalı Çalışma Alanları, 21.02.2013.

7. Yüksek, M.S., 1993. Yeraltı Madenciliğinde Aydınlatma ve TKİ OAL Çayırhan Müessesi Aydınlatma Şartları Etüdü, İTÜ Fen Bilimleri Enstitüsü, Yüksek Lisans Tezi, İstanbul.

8. TS 2248, Yeraltı Maden İşletmelerinde Genel Aydınlatma Kuralları, 25.02.1976.

9. Trotter, D.A., 1982. The Lighting of Underground Mines, Trans. Tech. Pub. Clausthal, Germany.

10. Yüksek, M.S., Ökten, G., 1994. Yeraltı Madenciliğinde Aydınlatma ve TKİ OAL, Çayırhan Müessesesi Genel Aydınlatma Şartlar1, Yerbilimleri-Geosound, N.25, 12/1994, s155-164, Adana.

11. Stabila LD 300 Lazer Metre El Kitabı, http://www.pentaotomasyon.com.tr

12. TES 1335 Ligh Meter El kitab1, http://www.primoinc.com/en/product/1607/TE S-1335. 
